\title{
'STOP BEFORE YOU BLOCK' RE-AUDIT OF PRACTICE IN A LONDON TEACHING HOSPITAL
}

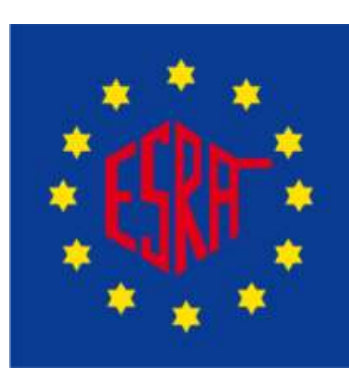

\author{
V. Woodham, K. Duraisamy, A. Pawa \\ Guy's and St Thomas' Hospital, London
}

\section{Background}

The Stop Before You Block (SBYB) campaign was started in 2011 after 67 incidences of wrong-sided blocks in the UK over a 15-month period. This constitutes a Never Event according to the National Patient Safety Agency and exposes patients to increased risk of nerve injury, local anaesthetic toxicity and wrong-site surgery.

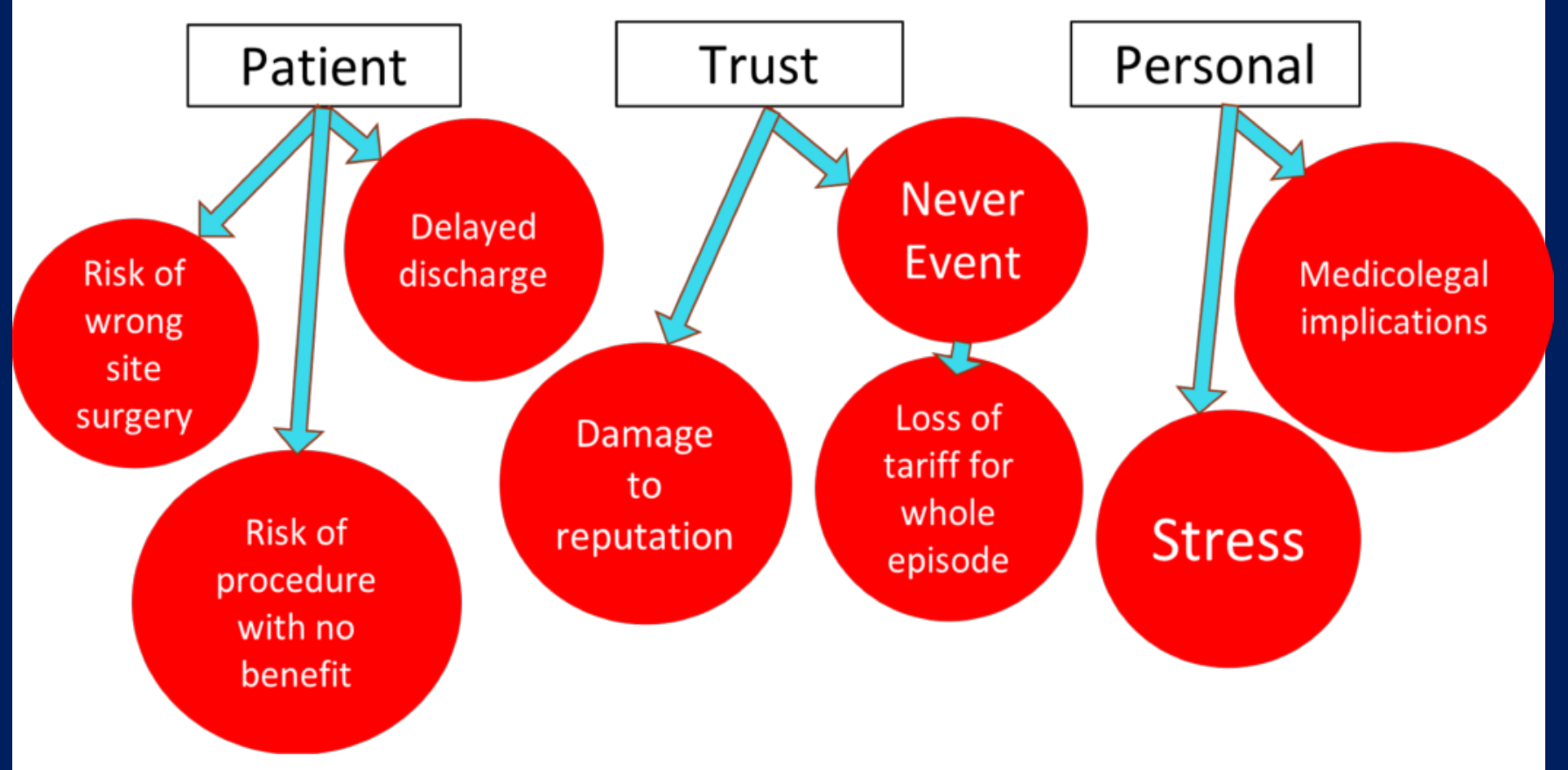

Fig. 1. Reasons highlighting the importance of the 'Stop Before You Block' campaign

Despite a visible campaign in our hospital, there were two wrong-sided blocks in the last two years.

The aim of the audit was to assess departmental compliance with SBYB and measure performance against previous results.

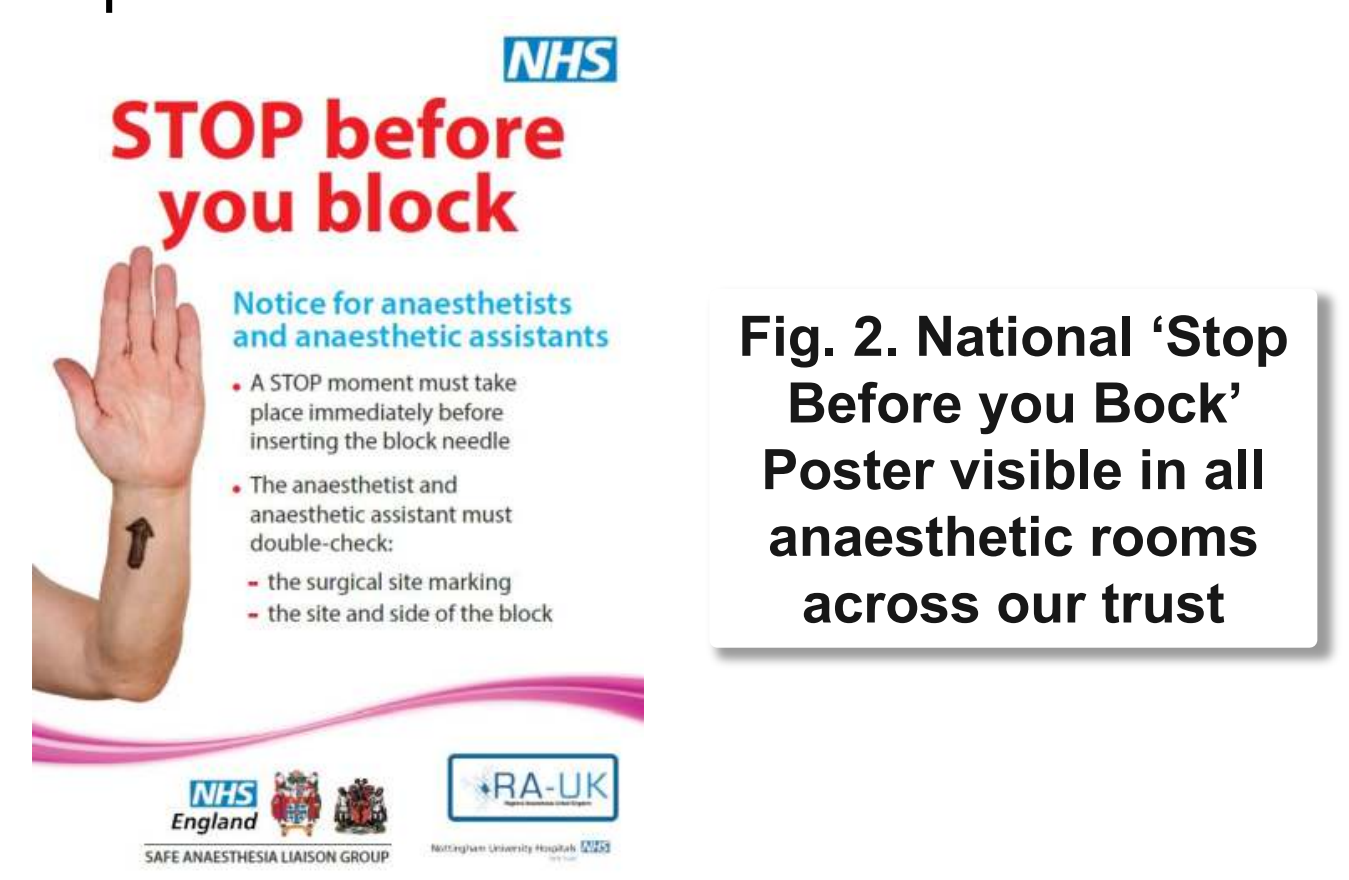

\section{Method}

Data was collected prospectively by nursing staff on regional nerve blocks preformed over a 3-month period.

Data collected included grade of anaesthetist, type of block and whether steps in SBYB were adhered to.

This was compared to data collected in 2016.

\section{Results}

Data was collected for 100 regional nerve blocks. In $76 \%$ (vs $93 \%$ in 2016) of cases the operative side was confirmed with the patient and consent form prior to the procedure and in $87 \%$ (vs $83 \%$ ) of cases the anaesthetist visualised and exposed the surgical mark prior to prepping the area.

However, only $57 \%$ (vs $55 \%$ ) of anaesthetists paused prior to needle insertion.

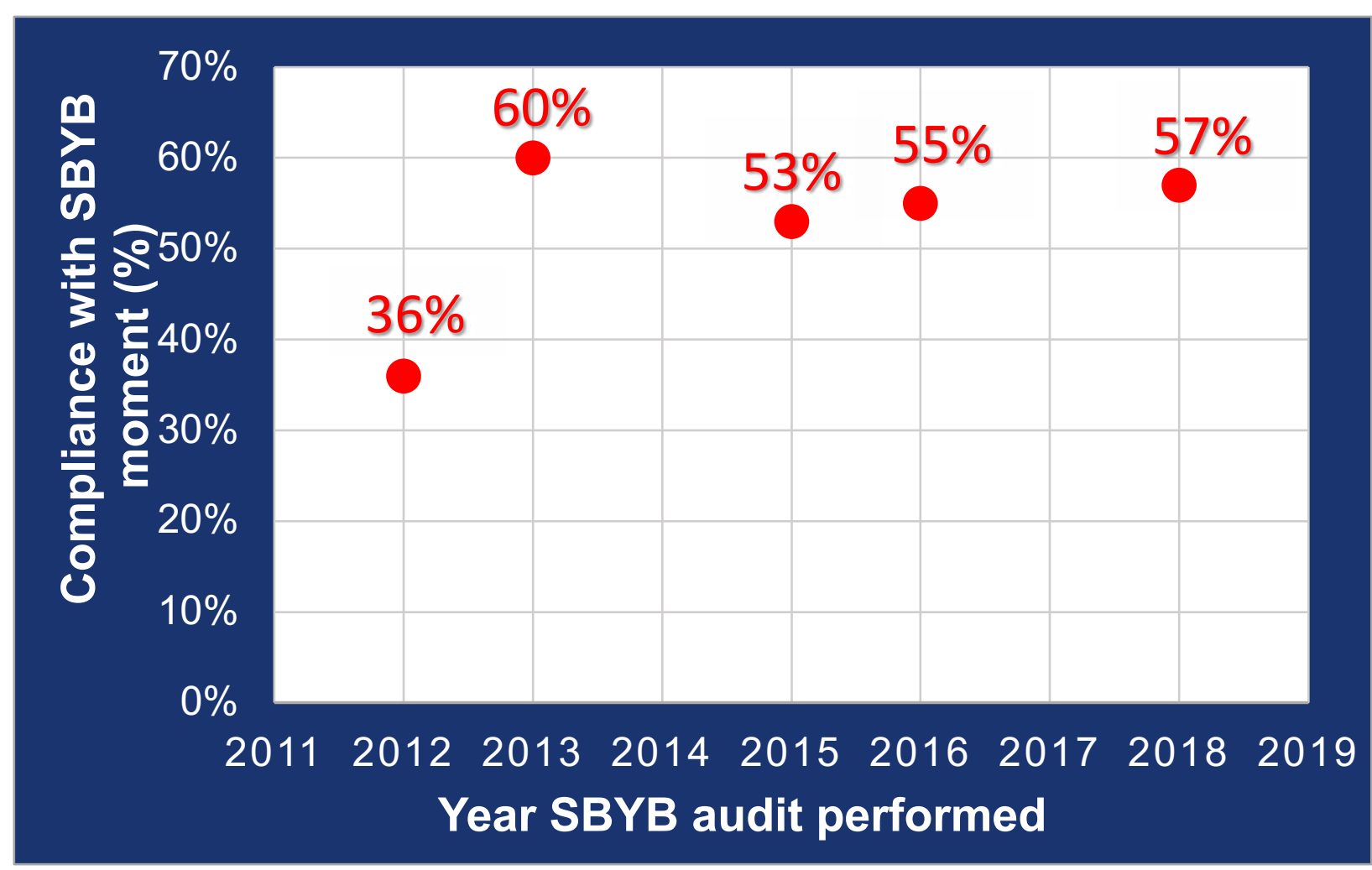

Fig. 3. Results from our SBYB audit across the last few years- showing static improvement in our compliance

\section{Discussion}

Despite recent wrong-sided blocks and frequent audit, no new interventions have been introduced and there has been no significant improvement in compliance since the last audit.

More needs to be done in order to reduce the risk of preventable patient harm. This may require an alternative approach i.e. Mock Before You Block or devoting further resources to the current campaign.

Fig. 4. Our new sterile drapes with 'Stop Before You Block' sticker aiming to encourage a 'Stop' moment prior to block

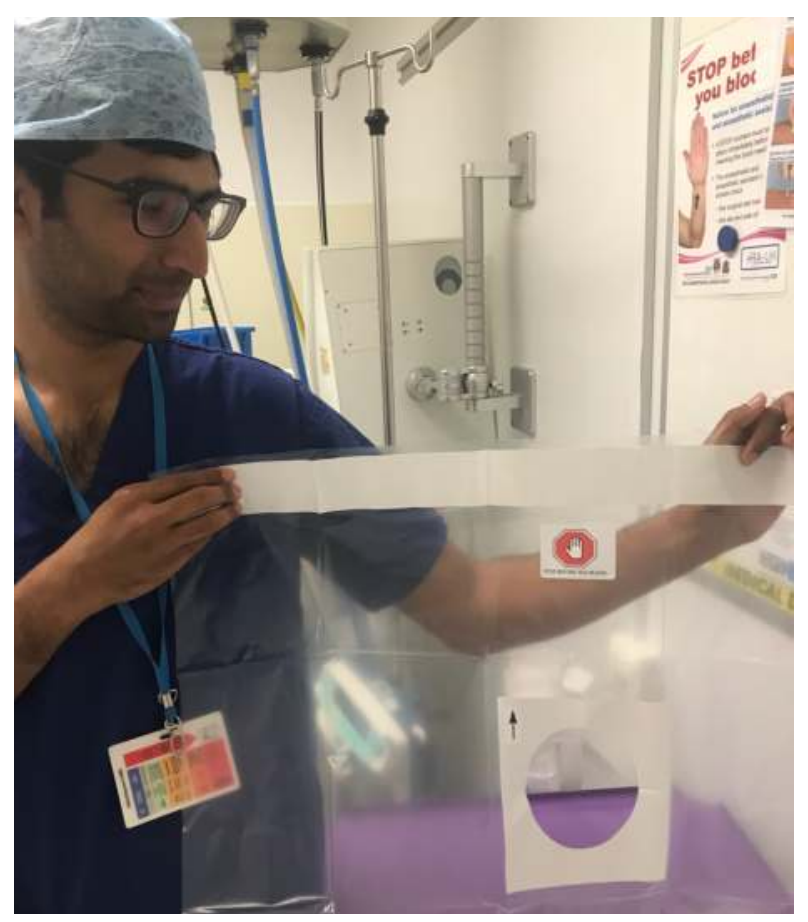

French J, Bedforth N, Townsley P. Stop before you block campaign. http://www.roca.ac.uk/standards-of-clinicalpractice/wrong-site-block. 2011. Published 2010. 